\title{
The mass mortality of blue mussels (Mytilus spp) from the Atlantic coast of France is associated with heavy genomic abnormalities as evidenced by flow cytometry
}

\author{
Benabdelmouna Abdellah ${ }^{1,{ }^{*}}$, Ledu Christophe ${ }^{1}$ \\ ${ }^{1}$ Ifremer, RBE-SG2M-LGPMM, Station de La Tremblade, avenue de Mus de Loup, F-17390 La \\ Tremblade, France \\ * Corresponding author : Abdellah Benabdelmouna, email address : Abdellah.Benabdelmouna@ifremer.fr
}

\begin{abstract}
:
Since 2014, France's blue mussel industry has been facing heavy mortality outbreaks (90-100\%) affecting both juveniles and adults. This report presents evidence of heavy genomic abnormalities associated with mortality outbreaks in blue mussels, Mytilus edulis-galloprovincialis, from the Atlantic coast of France. In this study, ploidy characteristics of hemic cells were investigated using Flow CytoMetry (FCM), revealing an unusual, broad continuum of ploidy distribution from hypodiploidy to tetraploidy. FCM was additionally used to evaluate, at individual and populations levels, different thresholds of genomic abnormality (GA\%) using the percentage of non-diploid nuclei. Individual mussels were considered to be abnormal when more than $10 \%$ of hemocytes in S-G2/M phase were present. At the population level, a threshold of $6 \%$ for the mean intensity of the abnormality is proposed, which means in the population, more than $6 \%$ of individual mussels have to present with more than $10 \%$ of their hemocytes in S-G2/M phase. GA\% was found to be significantly predictive of the final mortality. Based on the established thresholds, only two mussel stocks analyzed in this study were considered to have good cytogenetic quality, while all other stocks appeared to be affected. FCM offers a very powerful tool to help manage current blue mussel mortality in France. We also believe that annual and extensive determination of cytogenetic quality of wild and cultivated mussel beds along with exclusive use of FCM-qualified mussel seeds should be a priority.
\end{abstract}




\section{Graphical abstract}

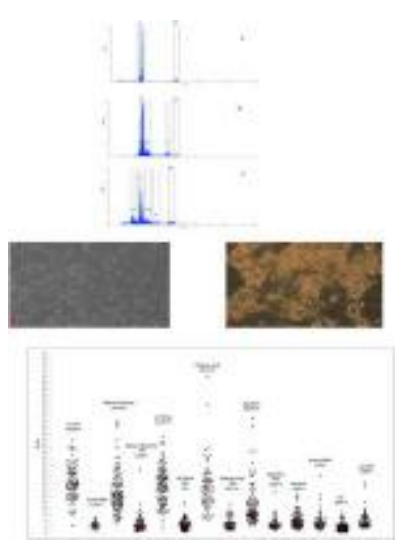

\section{Highlights}

- Since 2014, France's blue mussel industry has been facing heavy mortality outbreaks (90-100\%) affecting both juveniles and adults. Flow cytometry analyses evidenced heavy genomic abnormalities in association with mussels mortalities. Hemocytology identified neoplastic circulating cells in hemolymph. Threshold values at individual and population levels were defined to qualify the cytogenetic quality of mussels. Final mortality level is closely related to initial cytogenetic quality of mussel stocks.

Keywords : Mussels, mortality, cytogenetic quality, hemocytes, ploidy 


\section{Introduction}

Mussels are of great importance in the marine ecosystem as they actively filter the water and are a food source for many organisms including humans. Like other bivalves, mussels are frequently used in biomonitoring programs due to their biological characteristics and wide geographic distribution (Viarengo et al. 2007). Hence, the use of naturally occurring mussels is a very direct approach to in situ biomonitoring programs for environmental effects related to municipal, agricultural and industrial effluents. In France, in addition to this eco-sentinel action, mussels are also of great economic importance, and the blue mussel industry (Mytilus edulis and Mytilus galloprovincialis) produces more than 77,000 metric tons each year (FAO 2014). This industry relies completely on natural spatfall limited to the Atlantic coast, principally in the Pertuis Charentais zone and the Bourgneuf Bay (Goulletquer and Héral 1997). However, since 2014, the production of French blue mussels decreased dramatically because of sudden and atypical mass mortality outbreaks (90-100\%) for which the causes remained uncertain, and both juvenile and adult blue mussels were affected (Béchemin et al. 2015).

Mortality of both naturally occurring and cultured blue mussels has been reported in many other locations around the world (Fuentes et al. 1992; Fuentes et al. 1994, Myrand and Gaudreault 1995; Tremblay et al. 1998; Myrand et al. 2000). The extent of mortalities can be highly variable, and several stress-related factors have been investigated, including pathogens, pollution, temperature, food depletion and reproduction, leading to a preliminary conclusion that none of these factors can alone explain the observed mortalities. Several studies have already shown that the exposure of mussels to environmental contaminations gives rise to various DNA damages, including abnormalities in DNA content and distribution as well as progressive development of circulating aneuploid-polyploid cells in the hemolymph. Additionally, in several marine mollusks species including mussels, circulating aneuploid- 
polyploid cells in the hemolymph are also particularly observed during the development of a frequently fatal leukemia-like cancer disease called hemic (or disseminated) neoplasia (Elston et al. 1992; Landsberg 1996; Bihari et al. 2003; Vassilenko and Baldwin 2014). This malignant disease has been reported in 15 species of marine bivalves with a world-wide distribution including 4 species of oysters, 6 species of clams and 5 species of mussels (Elston et al. 1992; da Silva et al. 2005; Delaporte et al. 2008; Galimany and Sunila 2008; Le Grand et al. 2010; Diaz et al. 2011). The disease is characterized by enlarged, circulating, continuously dividing neoplastic cells in the hemolymph, which in late stages, completely replace normal hemocytes and penetrate various tissues such as connective tissue, gonads, the mantle and foot (Barber 2004; Carballal et al. 2015). This disease is commonly fatal and causes significant mortalities and decreases in market harvests in economically important species such as mussels, clams and cockles (Bower 1989; Elston et al. 1992; Barber 2004; Carballal et al. 2015). As reviewed by Barber (2004) and more recently by Carballal et al. (2015), different causes have been suggested regarding etiology of hemic neoplasia including genetic alterations, virus, retrotranspons, and contaminants. Although the exact role of chemical contamination is still controversial, several studies addressed the role of anthropogenic pollution and some of them finally suggested that exposures to environmental contaminants may be triggers for the disease by inducing rapid genetic instability promoting or at least accelerating disease progression (Arriagada et al. 2014). Whatever their origin, i.e., linked to genotoxic effect of pollutants and/or to a leukemia-like disease, the genomic abnormalities of circulating cells in the hemolymph of mussels can be reliably studied by FCM which is the most valuable technique for measuring the DNA content and for cell cycle analysis by permitting the characterization of cells in the G0/G1, S and G2/M phases and additionally detecting populations that have abnormal amounts of DNA (polyploid or aneuploid). Comparatively to other available methods (histology and hemocytology), this 
approach is now recognized as a non-tedious, non-subjective, cost-effective and high precision technique to study the observed DNA damage, cell cycle alterations and ploidy changes (Elston et al. 1990; Moore et al. 1991; Reno et al. 1994; da Silva et al. 2005).

In the context of mass mortality outbreaks affecting blue mussels in France since 2014, we hypothesized that the observed mortality was probably linked to their poor cytogenetic quality, particularly in terms of ploidy variations and cell cycle DNA alterations affecting circulating cells in the hemolymph. Indeed, in mussels experiencing the loss of normal hemocytes and their replacement by abnormal (DNA-damaged, aneuploid, polyploid, neoplastic) cells would at least leave the animal immunocompromised and, therefore, more susceptible to mortality. Additionally, besides their implication in defense and tissue repair, hemocytes are responsible for digestion, absorption and transportation of nutrients within the animal. Hence, any genomic abnormality concerning circulating cells of hemolymph would greatly decrease the overall fitness of the animal leading to starvation and then inducing its death (or at least increasing its susceptibility for mortality) (Barber 2004; Carballal et al. 2015). To explore this hypothesis, we used FCM to study the DNA content and cell cycle characteristics of hemocytes collected from various wild and cultivated blue mussels stocks along the French Atlantic coast. Biomonitoring of various areas situated in the Pertuis Charentais zone and Bourgneuf Bay was conducted by comparative FCM analysis of hemolymph cells before and after the mortality events that affected blue mussels $(M$. edulis/galloprovincialis) stocks during the winter-spring of 2015. Additionally, hemocytological analyses were performed on some selected contrasting samples to visually identify potential diseased cells based on their inability to adhere and their characteristic morphology. 


\section{Materials and Methods}

\section{2-1 Field sampling}

In the present work, the studied blue mussels are named M. edulis and M. galloprovincialis. Indeed, mussel aquaculture in France is based on these two very closely related species which can interbreed in areas of co-occurrence and produce fully fertile hybrids that are morphologically and physiologically intermediate between the parental taxa (Bierne et al. 2003). Adult specimens of 4-6 cm long were collected before the mortality in January and February of 2015 from 7 different mussel stocks distributed in four areas across the Pertuis Charentais zone and three others across the Bourgneuf Bay (Fig. 1). Each mussel stock was constituted of 300 adult mussels and was maintained alone in a separate tank and provided with 250-L per hour of unheated and UV-filtered seawater. The mortality events were declared finished when no dead mussels were recorded in hatchery condition and three months after the peak of mortality in the field. For each mussel stock, the final mortality level was calculated after counting dead and alive mussels in the hatchery condition. This final mortality level was also compared to that estimated in open field conditions by mussel farmers and state services. Finally, at this time, the same analyses accomplished before the mortality were applied again to surviving mussels collected from the same open field sites and also from some surviving mussels maintained in the experimental hatchery.

\section{2-2 Hemolymph collection, FCM and hemocytology}

Hemolymph samples were individually taken from 80-120 mussels per site and immediately used for FCM and hemocytological analyses. Hemolymph was withdrawn in a nondestructive manner from the adductor muscle of each individual mussel with sterile $1 \mathrm{~mL}$ syringe fitted with a 26 gauge needle. For each animal, a volume of approximately $0.2 \mathrm{~mL}$ of 
hemolymph was collected and stored temporarily in an Eppendorf microcentrifuge tube on ice to prevent clumping.

For FCM analysis, hemolymph samples were transferred into microtubes maintained on ice. For each individual mussel, $0.1 \mathrm{~mL}$ of hemolymph was used, without any fixation step, for nuclei extraction and staining. Each hemolymph sample was first diluted in $1 \mathrm{~mL}$ of ice-cold nuclei extraction buffer $\left(5 \mathrm{mM} \mathrm{MgCl}_{2}, 85 \mathrm{mM} \mathrm{NaCl}, 10 \mathrm{mM}\right.$ Tris, $0.1 \%$ Triton X100, pH 7). Extraction of nuclei was realized by detergent (Triton X-100) action and facilitated by several pipetting. Extracted nuclei were then purified by filtration through a 30 $\mu \mathrm{m}$ nylon sieve (Celltrics, Sysmex) to eliminate membranes and large clumps. Samples were then simultaneously treated with DNase-free RNase A (Sigma R4875, $50 \mu \mathrm{g} \mathrm{mL}{ }^{-1}$ ) and stained at room temperature for $45 \mathrm{~min}$ in the dark with propidium iodide (PI, Sigma, P4170) at a concentration of $50 \mu \mathrm{g} \mathrm{mL}^{-1}$ in a $2 \mathrm{~mL}$ final solution. For some selected samples showing contrasting FCM patterns, ploidy level estimations were also done by using nuclei from trout red blood cells (TRBC, Beckman Coulter, DNA Reference Calibrator, 629972) as an internal standard. In this case, $2 \mu 1$ of TRBC were mixed into each hemolymph sample and then the nuclei of both internal standard and sample were subjected to the same extraction and staining procedures as described above.

For each mussel stock, FCM analyses started right after the PI-staining period and lasted for 60-90 min where the PI staining was observed to be stable (da Silva et al. 2005). Analysis was performed on a CyFlow ${ }^{\circledR}$ Ml flow cytometer equipped with a $532 \mathrm{~nm}, 30 \mathrm{~mW}$ green laser (Sysmex, Sainte Geneviève des Bois, France). PI fluorescence, which is related to the DNA content of each nucleus, was detected on the FL3 detector (orange-red fluorescence detector at 550-600 nm). For each sample, 10,000 nuclei were counted at low flow rate (15 $\mu 1$ $\min ^{-1}$ ). Cell-cycle estimates were done using the method described in (da Silva et al. 2005) for removing doublets and debris. Thus, in order to distinguish nuclei in the G2/M phase from 
doublets of G0/G1 nuclei that have the same DNA content, FL3-area vs. FL3-width dot-plots were used to gate single nuclei. Thus a region (R1) was drawn on these dot-plot representations to discriminate single nuclei from doublets. After gating them on R1, single nuclei were next plotted on a FL3-area histogram on 1024 linear scale (Fig. 2B) and used to calculate the percentages of nuclei populations according to their DNA content. Peak positions were determined manually as described in Delaporte et al. (2008) by specific markers placed to estimate the percentage of normal diploid G0/G1 nuclei and non-diploid nuclei in both phase $\mathrm{S}$ and tetraploid G2/M stages. Based on preliminary data and according to the work of Elston et al. (1990) who used flow cytometry to characterize normal and abnormal mussels, we fixed an upper limit of $10 \%$ of non-diploid nuclei for a normal mussel. Beyond this limit, mussels were considered to be affected by genomic abnormalities.

Hemocytological analyses were conducted only for individuals that showed contrasting FCM profiles (pure diploids vs. non-diploids). For these selected individual mussels, $0.1 \mathrm{~mL}$ of hemolymph was processed as described in Metzger et al. (2015). Drops of hemolymph were allowed to settle onto a clean poly-L-Lysine coated glass slide and left undisturbed for $1 \mathrm{~h}$ at $10^{\circ} \mathrm{C}$ before morphological analysis using phase-contrast microscopy (Zeiss axioplan 2 imaging).

\section{2-3 Statistics}

Statistical analyses were processed with the software XLSTAT (Addinsoft, 2011). The data are expressed as the mean \pm standard error. Non-parametric tests were used for comparisons. Differences between mussel stocks in terms of percentages of non-diploid cells were analyzed with the Kruskall-Wallis test followed by paired comparisons with the Mann-Whitney test. The probability threshold was set at $\mathrm{p}<0.01$. 


\section{Results}

\section{3-1 Analyses before the mortality event}

\section{3-1-1 Flow cytometry analyses}

In total, approximately 1300 mussels were individually analyzed by FCM; among them 1200 presented with acceptable results (clearly distinguishable sample peaks, internal standard TRBC with CV\% below 3\%). In order to prevent excess background noise and cell clumping, we used an FCM protocol based on stained nuclei isolated from fresh (unfixed) hemocytes. Use of Triton X-100 is known to strip away the cell membrane and cytoplasm, leaving bare nuclei but giving tight DNA peaks. Additionally, filtration of nuclei through a $30 \mu$ mylon sieve greatly helped to eliminate clumps and doublets. This was evidenced when FL3-width vs. FL3-area dot plots were applied showing that doublets and debris were at low occurrence and that the analyzed particles were in their very large majority represented by single nuclei (figs 2-3, right panels). According to their FCM profiles based on gated single nuclei, and compared with the internal standard TRBC channel position, the analyzed mussels could be categorized into two groups. The first group is composed of normal mussels with FCM histograms showing a dominant population of diploid (2n) nuclei in the G0/G1 phase (Fig. 2). The second group is composed of mussels with FCM histograms presenting more complex patterns, showing, in addition to the normal diploid population of nuclei, additional populations of nuclei with a non-diploid ploidy level that all display aneuploidy patterns typical of previously described leukemia-like cancerous cells, including hypodiploid (1.4-1.8 n), hyperdiploid (2.2-2.4 n), hypotriploid (2.5-2.8 n) and hypotetraploid (3.8-3.9 n) ploidy. Although the very large majority of mussels with non-diploid peaks presented aneuploid peaks situated in the S and G2/M phases, some rare mussels also presented distinct peaks with nuclei in the hypodiploid (1.4-1.8 $\mathrm{n}$ ) range (Fig. 3). 
Accordingly, in this study, we focused on cell cycle analysis using only nuclei in the G0/G1 (diploid) versus S-G2/M (non-diploid) phases, which permitted us to calculate the percentage of non-diploid nuclei corresponding to each individual mussel and to describe its genomic status. Finally, the variation of this percentage among the different mussel stocks analyzed was investigated before and after the mortality outbreaks. The intensity of genomic abnormalities for each mussel stock, expressed as GA\%, was estimated by the value of the mean percentage of non-diploid nuclei detected among individual mussels. Additionally, the percentage of mussels with more than $10 \%$ of non-diploid nuclei was used to estimate the prevalence of abnormal mussels per stock.

FCM analysis conducted before the mortality outbreak on the seven mussel stocks showed contrasting results. For each mussel stock, distribution of individuals with various percentages of non-diploid nuclei is represented in Figure 4. The results were compared with the non-parametric test of Kruskal-Wallis with multiple pair comparisons of Dunn (Table 1). This showed significant differences between the tested groups $(K=526.365$, df $=6$, $p<$ 0.0001). The three analyzed mussel stocks from Bourgneuf Bay, namely, "le Fiol”, "Maison Blanche" and "la Plaine" as well as the mussel stock "Filière nord" from Pertuis Charentais were grouped together. These four stocks presented the highest levels of genomic abnormalities as evidenced by high values of GA\%, varying from 18 to $23 \%$. Additionally, the prevalence of abnormal mussels in these four mussel stocks was extremely high, varying from 90 to $98 \%$ of mussels having more than $10 \%$ of non-diploid nuclei. These four stocks constituted a separate group that was significantly different from the three remaining mussel stocks, which were also different from each other and were all from the Pertuis Charentais zone. Thus, "Aiguillon" exhibited an intermediate level of genomic abnormalities with a GA\% value of $12 \%$ and with a prevalence of abnormal mussels of $42 \%$, while "Lay" and "Boyard" showed no or very low genomic abnormalities with GA\% values varying from 3 to 
$6 \%$, respectively. Finally, it is noteworthy that the mussel stock from "Lay" appeared to be the only mussel stock that was initially totally free from any abnormal mussels with no individual mussel presenting with more than $10 \%$ of non-diploid nuclei.

\section{3-1-2 Hemocytology}

Hemocytological analyses were conducted on selected hemolymph samples collected from mussels with contrasting FCM profiles, i.e., histograms with only one G0/G1 peak versus various aneuploid peaks. Thus, normal blue mussels with FCM presenting only one G0/G1 diploid peak presented clear hemolymph samples with hemocytes presenting multiple pseudopodia that quickly attached to the glass slide (Fig. 5a). Alternatively, hemolymph collected from heavily abnormal mussels, with a very high mean of percentages of nondiploid nuclei, exhibited more cloudy hemolymph with numerous rounded and refractile cells showing a lack of attachment to the glass slide and presenting characteristics of previously described leukemia-like cells present in a fatal disease known as hemic (disseminated) neoplasia (Fig. 5b).

\section{3-1-3 Mortality survey}

After completion of the analyses before the mortality, the different mussels stocks maintained in the hatchery or reared in the field were affected by a mortality event with a peak recorded during April 2015. After this peak, chronic residual mortality followed and lasted for two months. It is interesting to note that, for each mussel stock, the final mortality level estimated in open field conditions by mussel farmers and state services was in general not drastically different from that we calculated in the controlled hatchery conditions after counting dead and alive mussels. Thus, in the controlled hatchery condition, final mortality levels of the different 
mussel stocks was 5\% for "Lay", 80\% for both "Maison blanche" and "la Plaine" and 90\% for "Le Fiol". The "Filière nord", "Aiguillon" and "Boyard" mussel stocks exhibited lower final mortality levels of 55,30 and $10 \%$, respectively.

\section{3-2 Analyses after the mortality event}

The mortality event was judged as finished in open field three months after the peak of mortality recorded during April 2015. By late August 2015, FCM analyses were performed again on surviving mussels collected in the field from the same mussel stocks analyzed before the mortality. Depending on the availability of surviving mussels in the hatchery condition, FCM analyses were also performed on some mussel stocks from this condition. For each mussel stock analyzed, no differences in term of FCM patterns were evidenced for the two conditions (not shown). The results obtained for mussel stocks from field conditions are represented in Figure 4. In this case, differences between stocks were not as evident as before the mortality. After the mortality event, according to the $10 \%$ upper limit of non-diploid nuclei, all of the mussel stocks analyzed appeared to not be affected by genomic abnormalities or only at very low intensities as evidenced by their low GA\% that varied from 3.7 to $6 \%$. Additionally, the prevalence of abnormal mussels decreased very clearly and varied from 0 to $8 \%$.

Finally, comparison of genomic abnormality levels (GA\%) obtained for the same mussel stock analyzed before versus after mortality showed that the mortality event was accompanied by preferential elimination of all (or the very large majority of) abnormal mussels with heavy genomic abnormalities (Fig. 4). Thus, after the mortality event, all of the mussel stocks, even those that were affected by initial high levels of genomic abnormalities (elevated GA\%), appeared to be released from genomic abnormalities and recovered GA\% values below $6 \%$. We then estimated that this value of GA\% corresponded to a threshold 
useful for the qualification at the population level of mussel stocks. Finally, very high and significant correlation was found between the final mortality of a particular mussel stock and its initial cytogenetic quality estimated by its corresponding initial GA\% value $(r=0.945$ and $\mathrm{P}=0.001)($ Fig. 6). 


\section{Discussion}

In France, this is the first description of heavy genomic abnormalities detected by mean of a broad and multi- site FCM survey in relation to a massive mortality outbreak affecting blue mussels (M. edulis/galloprovincialis). In our study, FCM revealed that abnormal mussels were characterized by production of hemocytes with a large array of ploidy levels from hypodiploidy to tetraploidy. This broad variation in DNA content of affected cells additionally corresponds to morphological and physiological changes in the hemocytes that were already described in numerous mollusk bivalves as typical of cancerous, leukemia-like cells. Unlike a previous study on Mytilus spp (most likely $M$. trossulus) that reported only distinct near tetraploidal and pentaploidal forms of neoplastic cells (Elston et al. 1990), our study showed that the G0/G1 ploidy peaks for the abnormal blue mussels' hemocytes varied over a continuum from hypodiploidy to hypotetraploidy similar to the observations made in several studies for the blue mussel, M. trossulus, (Vassilenko and Baldwin 2014) and cockles, Cerastoderma edule (da Silva et al. 2005; Le Grand et al. 2010; Diaz et al. 2011), where even wider variations in ploidy from $1.3 \mathrm{n}$ to $9.6 \mathrm{n}$ were observed. Furthermore, a minor hypodiploid population of cells was detected in some rare tested samples of abnormal mussels. The significance of this population of cells is unknown, although some authors suggest that these hypodiploid cells might represent the initial stage of neoplasia (da Silva et al. 2005). Additional research is necessary to confirm this hypothesis, but it is still interesting to note the presence of these cell populations because this was also the case in previous studies in both Mytilus spp (Elston et al. 1990, Moore et al. 1991; Bihari et al. 2003), cockles and the soft shell clam, M. arenaria (Reno et al. 1994).

In various mollusk species, FCM has been extensively used to characterize ploidy variations between normal and abnormal cells (Moore et al. 1991; Reno et al. 1994; da Silva et al. 2005; Smolarz et al. 2005; Delaporte et al. 2008; Siah et al. 2008, Le Grand et al. 2010). 
FCM has been shown to be a powerful tool for accurate diagnosis of hemic neoplasia in the blue mussels, M. edulis/trossulus (Elston et al. 1990), in the soft shell clam, M. arenaria (Reno et al. 1994; Delaporte et al. 2008), and in the common cockle, C. edule (da Silva et al. 2005; Le Grand et al. 2010). Reno et al. (1994) used FCM to characterize the cell cycle histogram for negative and heavily affected clams. Although the normal percentage of hemocytes in phase $\mathrm{S}$ and $\mathrm{G} 2 / \mathrm{M}$ stages in a non-diseased individual remains unknown because the hematopoiesis process in mollusks is unknown, the authors proposed that nonleukemic soft shell clams diagnosed by hemocytology could have approximately $6 \%$ of nuclei in S-G2/M phases. During a broader survey, Delaporte et al. 2008 agreed with these results and proposed a threshold value to define the disease status of the individual clam and clam populations. They suggested that individual clams were considered to be affected by hemic neoplasia when presenting at least $20 \%$ of hemocytes in $\mathrm{S}-\mathrm{G} 2 / \mathrm{M}$ phases and negative when presenting less than $5 \%$ of hemocytes in $\mathrm{S}-\mathrm{G} 2 / \mathrm{M}$ phases. Additionally, at the population level, the authors proposed a threshold of $15 \%$ for the mean intensity of the disease, which means several individual clams in the population have to present with more than $20 \%$ of their hemocytes in $\mathrm{S}-\mathrm{G} 2 / \mathrm{M}$ phases. In this present work on blue mussels, $M$. edulis/galloprovincialis, based on our preliminary data and according to Elston et al. (1990) who also used FCM to characterize normal and abnormal mussels, we fixed an upper limit of $10 \%$ of non-diploid nuclei for a normal mussel. We then considered that beyond this limit, mussels were considered as abnormal and affected by heavy genomic abnormalities. It is important to note that this threshold should be considered as a first estimation that could probably be more precisely determined in future works by systematically combining FCM and light microscopy methods (hemocytology and histology). Indeed, as natural replication of the DNA occurs during mitosis, healthy animals always contain a low proportion of nondiploid nuclei making it difficult to differentiate normal cells in mitotic division from 
neoplastic cells. Additionally, false negative or positive diagnoses cannot be excluded as normal cell-division rate is also expected to vary seasonally and among sites (Reno et al. 1994; Delaporte et al. 2008; Le Grand et al. 2010).

At a population level, FCM results obtained before and after the mortality outbreak showed that a threshold of $6 \%$ of mean GA\% could be adopted for the qualification of the cytogenetic status of a mussel stock. Mussel stocks analyzed before the mortality and presenting GA\% values under this threshold exhibited no genomic abnormalities with normal FCM histograms and hemocytes and presented very low mortality levels, while mussel stocks with GA\% values above this threshold presented with high mortality levels and exhibited atypical hemocytes with various levels of genomic abnormalities, illustrated by FCM histograms comprising various aneuploid and polyploid peaks. According to this threshold, it appears that the mussel stocks "Lay" and, in a lesser level, "Boyard" were the only ones that could be considered as having good genomic quality with no or an undetectable level of disease. Alternatively, all of the other mussel stocks analyzed during this survey should be considered as having poor genomic quality with high levels of disease. Interestingly, it appears that all of the analyzed mussel stocks cultivated in Bourgneuf Bay and the majorities of those cultivated in the north of Pertuis Charentais were of poor cytogenetic quality and exhibited very high mortality levels. The only two mussel stocks with good performances were either from a very isolated site (Lay) or from the southern part of Pertuis Charentais (Boyard). This could be explained by hydrodynamic transportation of a causative agent of mortality. Indeed, as extensively reviewed by Barber (2004) and Carballal et al. (2015), several studies demonstrated that hemic neoplasia in bivalves is transmissible between individuals and suggested an infective etiology with in particular the implication of a viral, retroviral, agent. Very recently, in a study with clams $M$. arenaria, it has been clearly demonstrated that this fatal contagious leukemia-like disease was spreading between animals 
in the marine environment as a clonal transmissible cell derived from a single original clam. The genotypes of the neoplastic cells all differed from the genotypes of their host animals and are identical or very closely related to each other (Metzger et al. 2015). The authors concluded that the individual leukemias are not derived by independent oncogenic transformation of cells within each host, but instead they come from a single genetically unrelated parent. In animals, very rare cases of cancer transmission by a contagious cell line have been known among them the canine transmissible venereal tumor (Murgia et al. 2006) and the Tasmanian devil facial tumor disease (Pearse and Swift 2006). The same phenomenon could probably be implicated in the current blue mussel mortality outbreaks in France. However, additional molecular studies with genetic markers are still needed to reach this conclusion.

Normally, disseminated neoplasia is rare in M. galloprovincialis and present (but at low prevalence) in M. edulis. In both species, this disease has not been generally associated with mortalities (Elston et al. 1992). Nevertheless, this disease causes epizootic mortalities in another related mussel species, M. trossulus (Galimany and Sunila 2008). In this context, the new and abnormal mortality outbreaks affecting blue mussels in France since 2014 highlight an unexpected and unusual fragility of French blue mussel stocks and raise serious questions about the origin of this phenomenon and its negative impacts not only on the future of mussel culture activity but also on the entire ecosystems where it occurs. Several non-exclusive hypotheses could be presented to explain this unfamiliar fragility and additional studies are still necessary to conclude. Among the hypothesis, in addition to a potential horizontal contamination occurring at intraspecific level, i.e. from affected to naive M. edulis individuals, interspecific hybridizations of larger than expected extent could play a role as Fuentes et al. (2002) suggested the existence of a depressed immune system in hybrid mussels (Mytilus edulis / Mytilus galloprovincialis), explaining their higher susceptibility to mortality 
compared with mussels from pure crosses. This hypothesis is reinforced by the fact that the Atlantic coast of France is an important hybridization zone between $M$. edulis and $M$. galloprovincialis (Bierne et al. 2003). By the same logic, deliberate introduction of the more susceptible mussel species $M$. trossulus, for aquaculture testing or accidentally through uncontrolled marine transportation, followed by its interspecific hybridization with native blue mussels could also be examined as possible cause of the currently observed fragility of blue mussels stocks in France. Consequently, additional studies using molecular markers should be performed. Finally and most probably, natural and anthropogenic pollution could also play a role as many studies have addressed its potential implication in inducing various genomic abnormalities in bivalve mollusks (Bihari et al. 2003; Barranger et al. 2014) and potentially initiating or accelerating disseminated neoplasia (Barber 2004; Carballal et al. 2015). Thus, leukemia in mussels (M. edulis) was reported to be elevated at sites with high industrial activity compared to reference sites (St.-Jean et al. 2005). Other studies clearly linked leukemia with industrial activity and other anthropogenic impacts (Kagley et al. 2003; St.-Jean et al. 2005; Muttray et al. 2012; Böttger et al. 2013). As an example, Muttray et al. (2012) found evidence that M. arenaria leukemia prevalence was higher at sites downstream of intensive high acreage potato farming, where they detected pesticide (insecticide) residues in the sediment, compared to low intensity estuaries, where pesticide residues were not detected. Although the hypothesis of synergy between an infective agent and pollutants to induce mortality by disseminated neoplasia was not unquestionably demonstrated, as assumed by Arriagada et al. (2014), we also think that exposures to environmental contaminants may be triggers for the disease by inducing rapid genetic instability and so could promote or at least accelerate disease progression.

In this study, FCM analyses detected heavy genomic abnormalities in association with massive mortality outbreaks affecting French blue mussel stocks. It is noteworthy that mussel 
stocks exhibited final mortality levels that were very significantly correlated to their initial cytogenetic quality (GA\%). Thus, FCM approach appears to be a very powerful tool to help manage current mussel mortality in France. This should be performed by combining two complementary approaches. The first one implies extensive determination of cytogenetic quality of wild and cultivated mussel beds with the aim of preserving those with good quality and to eliminate/reduce the ones with poor cytogenetic quality. The second approach implies that only FCM-qualified juveniles that show good cytogenetic quality should be used as seeds in cultured stocks. Additionally, because transmission could be facilitated or accelerated by human intervention, as seed stocks are transplanted between sites along the coast at several times, quarantine and sanitary management rules should be adopted and effectively applied, at least for the cultivated mussel stocks. 


\section{Acknowledgements:}

The authors are grateful to Hubert Palvadeau, James Grison, S. Robert and J-F Pépin for help in mussel stocks sampling and to Stéphane Guesdon for providing the map. This work was co-funded by the French DPMA (Direction des pêches maritimes et de l'aquaculture, Convention DPMA 2015- IFREMER 14/1211577/F) and by Ifremer (action Amélioration par les modifications de la ploïdie, A070212F). 


\section{References}

Arriagada, G., Metzger, M.J., Muttray, A., Sherry, J., Reinisch, C., Street, C., Lipkin, W.I., Golf, S.P., 2014. Activation of transcription and retrotransposition of a novel element Steamer in neoplastic hemocytes of the mollusk Mya arenaria. Proc. Natl. Acad. Sci. 111: $14175-14180$.

Barber, B., 2004. Neoplastic diseases of commercially important marine bivalves. Aquat. Living Resour. 17, 449-466.

Barranger, A., Akcha, F., Rouxel, J., Brizard, R., Maurouard, E., Pallud, M., Menard, D., Tapie, N., Budzinski, H., Burgeot, T., Benabdelmouna, A., 2014. Study of genetic damage in the Japanese oyster induced by an environmentally-relevant exposure to diuron: evidence of vertical transmission of DNA damage. Aquat. Toxicol. 146 : 93104.

Béchemin, C., Soletchnik, P., Polsenaere, P., Le Moine, O., Pernet, F., Protat, M., Fuhrman, M., Quéré, C., Goulitquer, S., Corporeau, C., Lapègue, S., Travers, A., Morga, B., Garrigues, M., Garcia, C., Haffner, P., Dubreuil, C., Faury, N., Baillon, L., Baud, JP., Renault. T., 2015. Episodes de mortalité massive de moules bleues observés en 2014 dans les Pertuis charentais. Bulletin épidémiologique, santé animale et alimentation, $67: 6-9$.

Bihari, N., Mičić, M., Batel, R., Zahn, R.K., 2003. Flow cytometric detection of DNA cell cycle alterations in hemocytes of mussels (Mytilus galloprovincialis) off the Adriatic coast, Croatia. Aquat. Toxicol. 64, 121-129.

Bierne, N., Daguin, C., Bonhomme, F., David, P., Borsa, P., 2003. Direct selection on allozymes is not required to explain heterogeneity among marker loci across a Mytilus hybrid zone. Mol. Ecol. 12: 2505-2510. 
Böttger, S.A., Amarosa, E.J., Geoghegan, P., Walker, C.W., 2013. Chronic natural occurrence of disseminated neoplasia in select populations of the soft-shell clam, Mya arenaria, in New England. Northeast. Nat. 20: 430-440.

Bower, S., 1989. The summer mortality syndrome and haemic neoplasia in the blue mussels (Mytilus edulis) from British Columbia. Can. Tech. Rep. Fisheries Aquat. Sci. 1703, $1-65$.

Carballal, M.J., Barber, B.J., Iglesias, D., Villalba, A., 2015. Neoplastic diseases of marine bivalves. J. Invertebr. Pathol. 131: 83-106.

da Silva, P.M., Soudant, P., Carballal, M.J., Lambert, C., Villalba, A., 2005. Flow cytometric DNA content analysis of neoplastic cells in haemolymph of the cockle Cerastoderma edule. Dis. Aquat. Organ. 67, 133-139.

Delaporte, M., Synard, S., Pariseau, J., McKenna, P., Tremblay, R., Davidson, J., Berthe, F.C., 2008. Assessment of haemic neoplasia in different soft shell clam Mya arenaria populations from eastern Canada by flow cytometry. J. Invertebr.Pathol. 98: $190-197$.

Diaz, S., Villalba, A., Insua, A., Soudant, P., Fernandez-Tajes, J., Mendez, J., Carballal, M.J., 2011. Disseminated neoplasia causes changes in ploidy and apoptosis frequency in cockles Cerastoderma edule. J. Invertebr. Pathol. 113, 214-219.

Elston, R.A., Drum, A.S., Allen, S.K., 1990. Progressive developmentof circulating polyploid cells in Mytilus with hemic neoplasia. Dis.Aquat. Org. 8: 51-59.

Elston, R.A., Moore, J.D., Brooks, K., 1992. Disseminated neoplasia of bivalve molluscs. Rev Aquat. Sci. 6: 405-66. 
FAO, Fisheries and aquaculture software. FishStatJ - software for fishery statistical time series. FAO Fisheries and Aquaculture Department Rome http://www.fao.org/fishery/statistics/software/fishstatj/en, 2014.

Fuentes, J., Reyero, I., Zapata, C., Alvarez, G., 1992. Influence of stock and culture site on growth rate and mortality of mussels (Mytilus galloprovincialis Lmk.) in Galicia, Spain. Aquaculture 105, 131-142.

Fuentes, J., Reyero, I., Zapata, C., Alvarez, G., 1994. Production traits of the mussel Mytilus galloprovincialis cultured in Galicia (NW of Spain): relative effects of source of seed and growing environment. Aquaculture 122, 19-31.

Fuentes, J., Lopez, J. L., Mosquera, E., Vazques, J., Villalba, A., Alvarez, G., 2002. Growth, mortality, pathological conditions and protein expression of Mytilus edulis and M. galloprovincialis crosses cultured in the Ria de Arousa (NWSpain). Aquaculture 213: $233-251$.

Galimany, E. Sunila, I., 2008. Several cases of disseminated neoplasia in mussels Mytilus edulis (L.) in western long island sound. J. Shellfish Res. 27 (5): 1201-1207.

Goulletquer, P., Héral, M., 1997. Marine molluscan production trends in France: from fisheries to aquaculture. NOAA Technical report NMFS 129: 137-164.

Kagley, A.N., Snider, R.G., Krishnakumar, P.K., Casillas, E., 2003. Assessment of seasonal variability of cytochemical responses to contaminant exposure in the blue mussel Mytilus edulis (complex). Arch. Environ. Contam. Toxicol. 44:43-52.

Landsberg J.H., 1996. Neoplasia and biotoxins in bivalves: is there a connection? J. Shellfish Res. 15, 203-230. 
Le Grand, F., Kraffe, E., de Montaudouin, X., Villalba, A., Marty, Y., Soudant, P., 2010. Prevalence, intensity, and aneuploidy patterns of disseminated neoplasia in cockles (Cerastoderrna edule) from Arcachon bay: seasonal variation and position in sediment. J. Invertebr. Pathol. 104, 110-118.

Metzger, M.J., Reinisch, C., Sherry, J., Goff, S.P., 2015. Horizontal Transmission of Clonal Cancer Cells causes Leukemia in Soft-Shell Clams. Cell 161: 255-263.

Moore, J. D., Elsterr, R.A., Drum, S., and Wilkinson, M.T., 1991. Alternate pathogenesis of systemic neoplasia in the bivalve mollusk Mytilus. J. Invertebr. Pathol. 58: 231-243.

Murgia, C., Pritchard, J.K., Kim, S.Y., Fassati, A., Weiss, R.A., 2006. Clonal origin and evolution of a transmissible cancer. Cell 126:477-487.

Muttray, A., Reinisch, C., Miller, J., Ernst, W., Gillis, P., Losier, M., Sherry, J., 2012. Haemocytic leukemia in Prince Edward Island (PEI) soft shell clam (Mya arenaria): Spatial distribution in agriculturally impacted estuaries. Sci. Total Environ. 424: $130-142$.

Myrand, B, Gaudreault, J., 1995.Summer mortality of blue mussels (Mytdus edulis Linnaeus, 1758) in the Magdalen Islands (southern Gulf of St Lawrence, Canada). J. Shellfish Res. 14: 395-404.

Myrand, B., Guderley, H., Himmelman, J., 2000. Reproduction and summer mortality of blue mussels Mytilus edulis in the Magdalen Islands, southern Gulf of St. Lawrence. Mar Ecol. Prog. Ser. Vol. 197: 193-207.

Pearse, A.M., Swift, K., 2006. Allograft theory: transmission of devil facial tumour disease. Nature 439: 549. 
Reno, P.W., House, M., Illingworth, A., 1994. Flow cytometric and chromosome analysis of softshell clams, Mya arenaria, with disseminated neoplasia. J. Invertebr. Pathol. 64:163-172.

Siah, A., Dohoo, C., McKenna, P., Delaporte, M., Berthe, F.C., 2008. Selecting a set of housekeeping genes for quantitative real-time PCR in normal and tetraploid hemocytes of soft-shell clams. Mya arenaria. Fish Shellfish Immuno1. 25: 202-207.

Smolarz, K., Renault, T., Soletchnik, P., Wolowicz, M., 2005. Neoplasia detection in Macoma balthica from the Gulf of Gdansk: comparison of flow cytometry, histology and chromosome analysis. Dis. Aquat. Org. 65, 187-195.

St.-Jean, S.D., Stephens, R.E., Courtenay, S.C., Reinisch, C.L., 2005. Detecting p53 family proteins in haemocytic leukemia cells of Mytilus edulis from Pictou Harbour, Nova Scotia, Canada. Can. J. Fish. Aquat. Sci. 62: 2055-66.

Tremblay, R., Myrand, B., Sevigny, J.M., Guderley, H., 1998. Bioenergetic and genetic parameters in relation to susceptibility of blue mussels, Mytilus edulis (L) to summer mortality. J. Exp. Mar. Biol. Ecol. 221: 27-58.

Vassilenko, E., Baldwin, S.A., 2014. Using flow cytometry to detect haemic neoplasia in mussels (Mytilus trossulus) from the Pacific Coast of Southern British Columbia, Canada. J. Invertebr. Pathol. 117: 68-72.

Viarengo, A., Lowe, D., Bolognesi, C., Fabbri, E., Koehler, A., 2007. The use of biomarkers in biomonitoring: a 2-tier approach assessing the level of pollutant induced stress syndrome in sentinel organisms. Compos. Biochem. Phys. C 146, 281-300. 


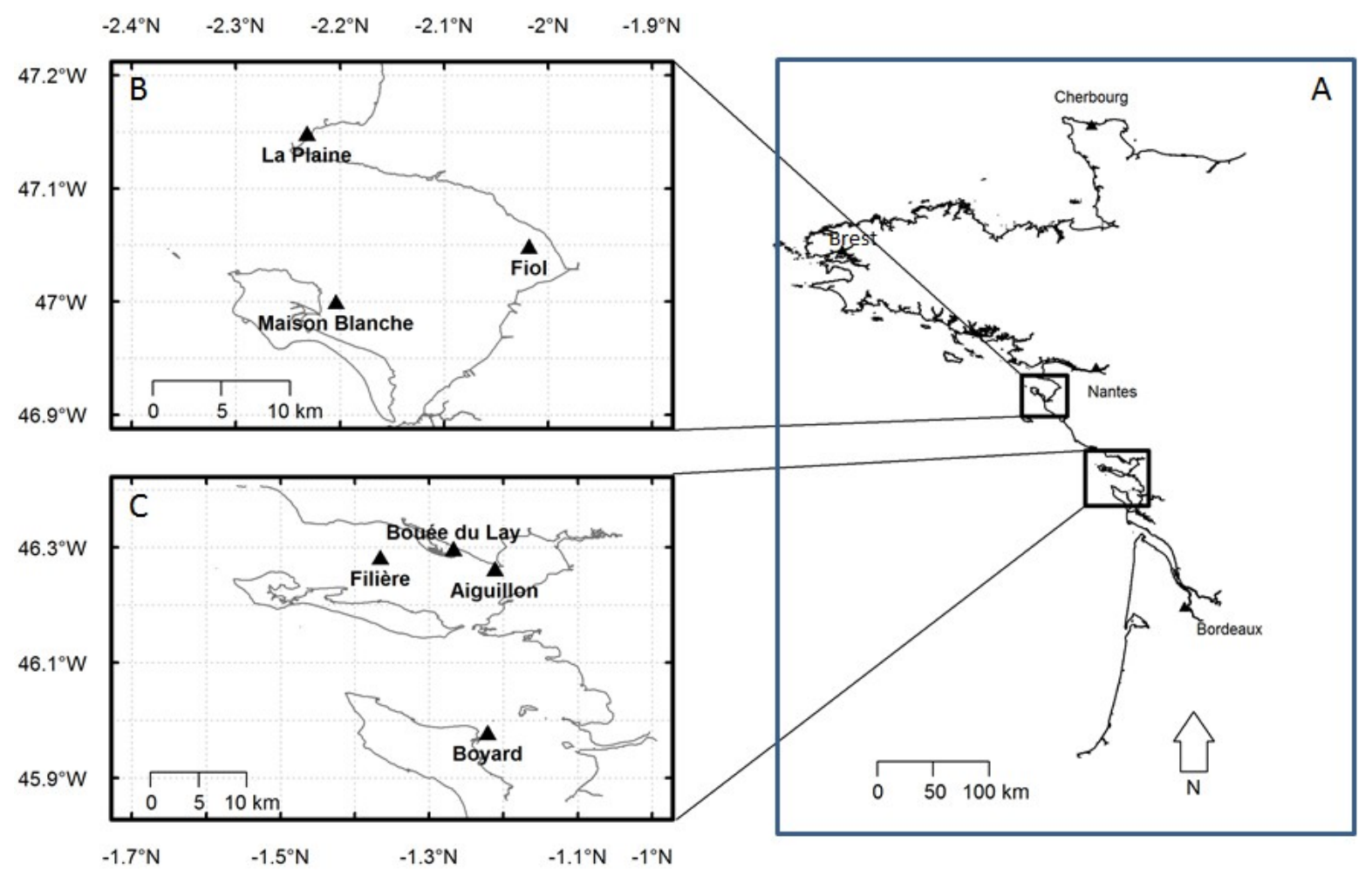

Figure 1. Locations of the sampled blue mussel stocks on Atlantic coast of France (A). Three mussel stocks were sampled in Bourgneuf Bay (B): la Plaine, Maison Blanche and le Fiol. Four mussel stocks were sampled in Pertuis Charentais zone (C): Filières, Bouée du Lay, Aiguillon and Boyard. 

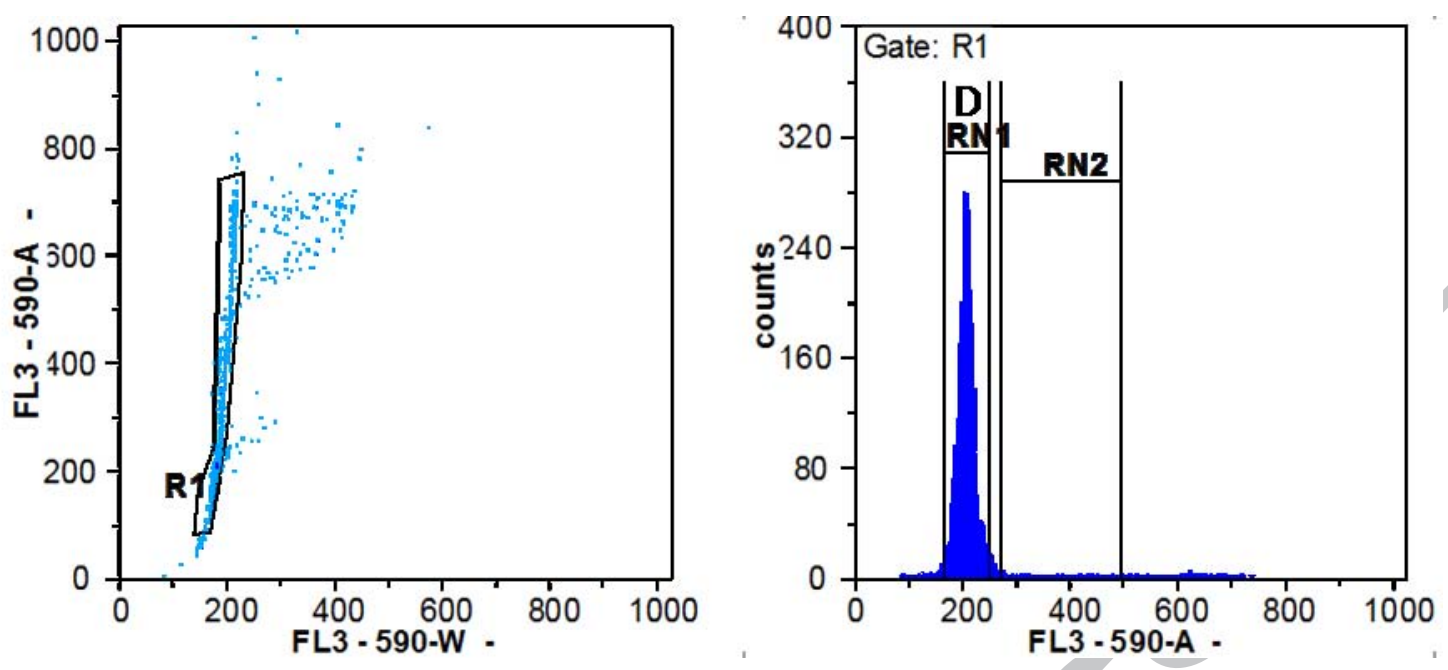

Figure 2. Flow cytometry histograms of propidium iodide stained hemolymph nuclei from normal blue mussels. Left panel: gating of single nuclei on a width vs area FL3 cytogram. Single particles are largely dominant and gated in region R1 while doublets and other higher associations are represented on the right of R1. Right panel: histogram of propidium iodide fluorescence of gated single nuclei. Markers RN1 and RN2 were placed to estimate the percentage of nuclei in diploid (D) and non-diploid phases, respectively. 

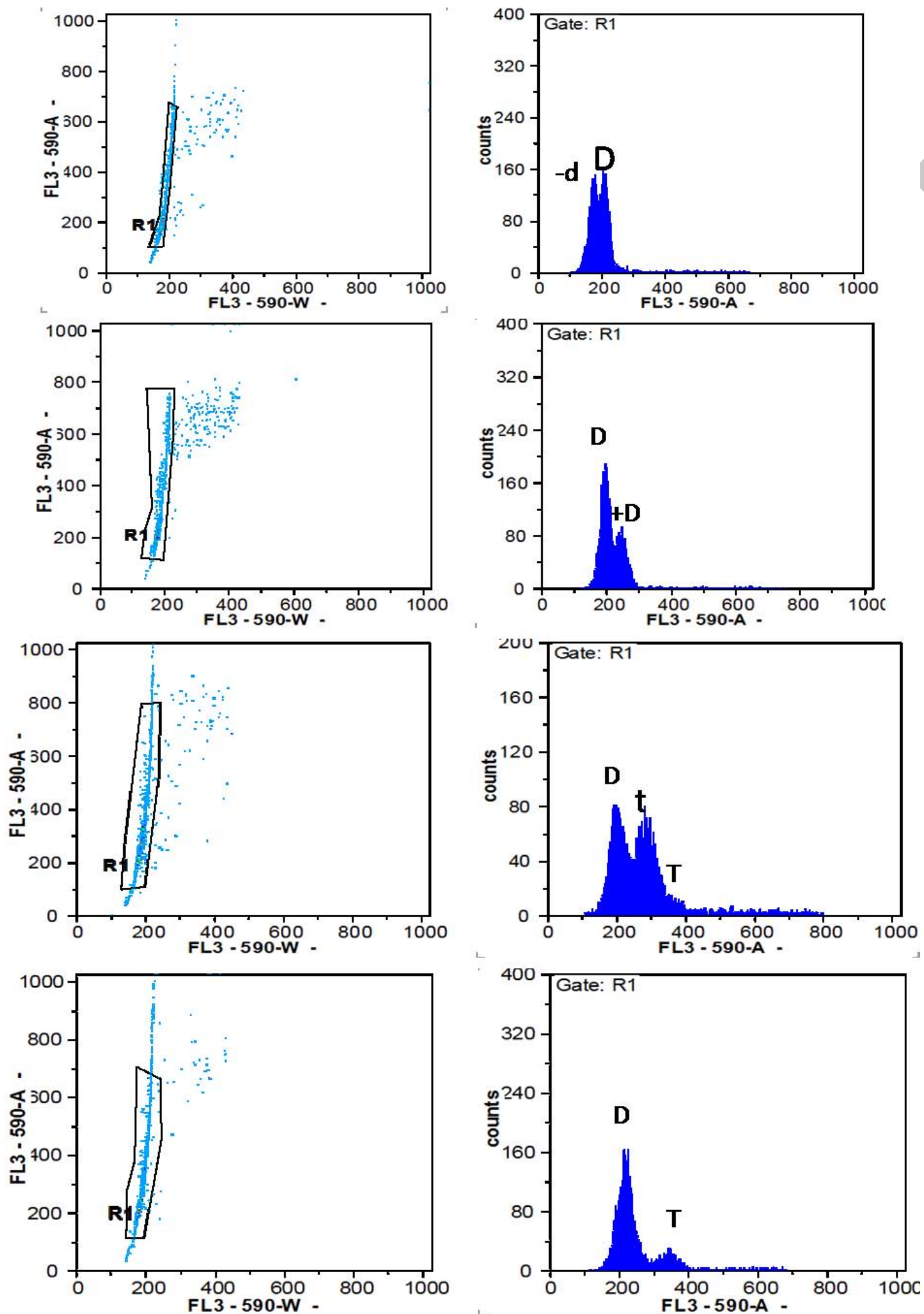

Figure 3. Flow cytometry histograms of propidium iodide stained hemolymph nuclei isolated from abnormal blue mussels. Left panels: gating of single nuclei on width vs area FL3 cytograms. Right panels: histograms of propidium iodide fluorescence of gated single nuclei showing diploid (D) nuclei in addition to various aneuploid peaks in the range of hypo-diploid (-d), hyper-diploid (+D), triploid (t) and hypotetraploid (T) levels. 


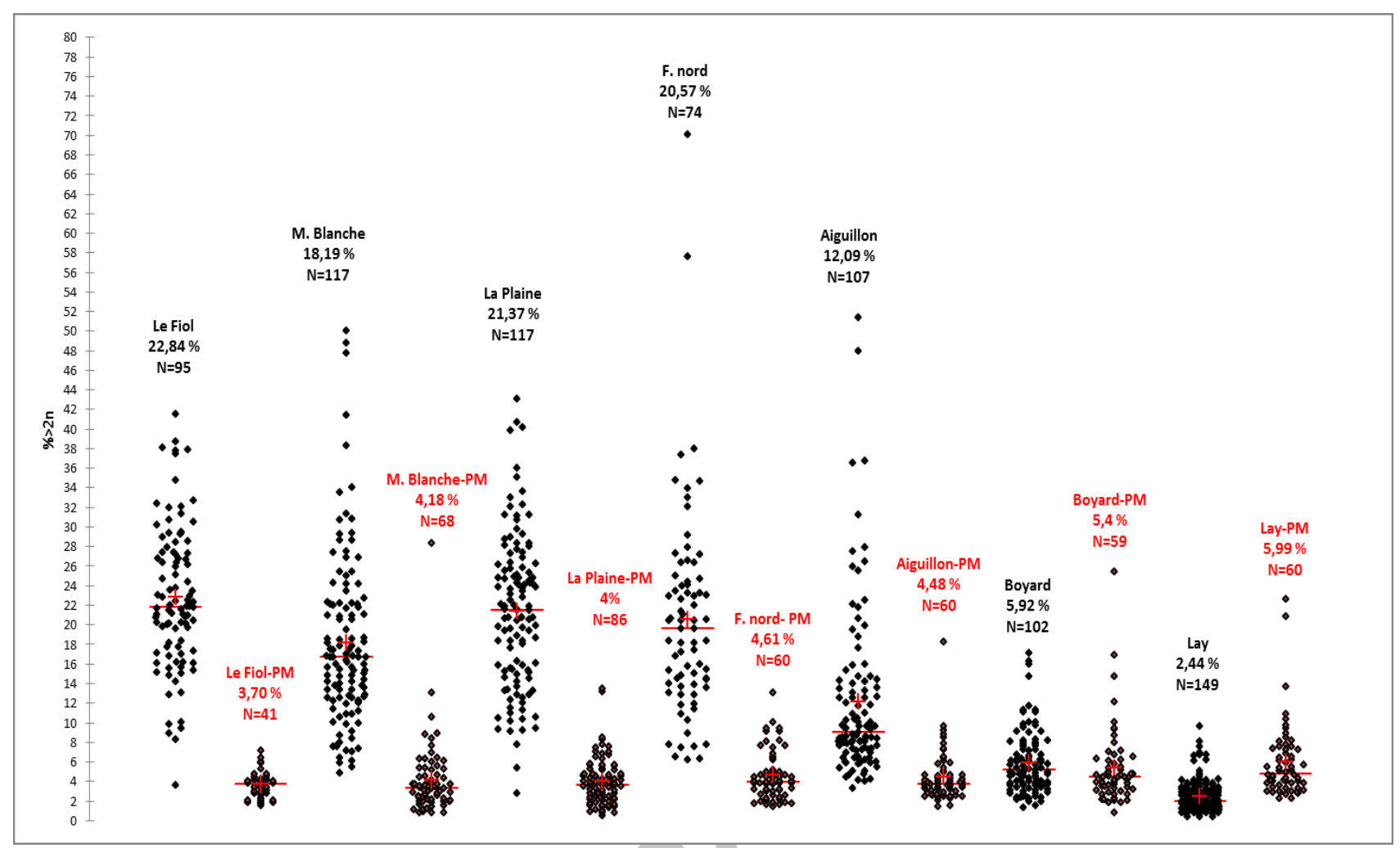

Figure 4. Scattergram representation of the variation of the non-diploid nuclei percentages within and between the different mussel stocks analyzed before and after the mortality event. Mussel stocks analyzed after the mortality event are in red and marked PM (post-mortality). Values under mussel stock names correspond to GA\% and indicate the mean percentage of non-diploid nuclei per mussel stock. $\mathrm{N}$ is the number of analyzed mussels per stock. 

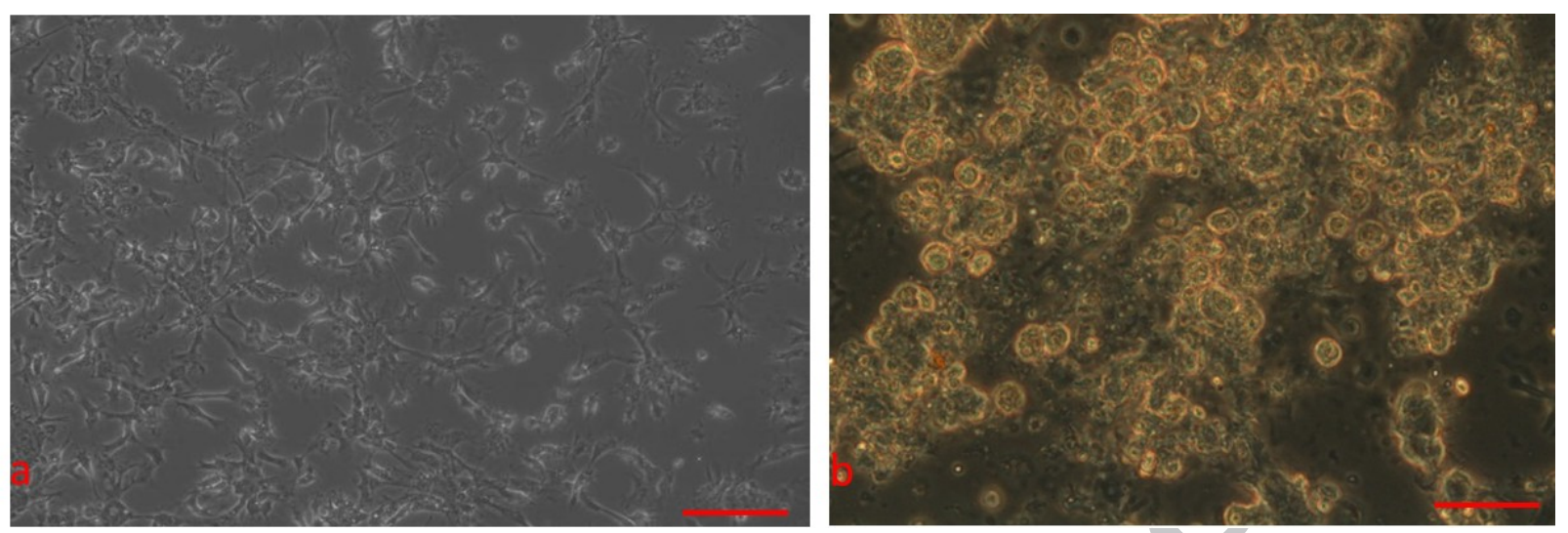

Figure 5. Light-microscopic photos of hemolymph cells from normal and abnormal blue mussels (M. edulis/galloprovincialis). (a) Hemolymph from a normal mussel showing attachment of hemocytes to the glass slide and extension of pseudopodia. (b) Hemolymph from a diseased mussel showing lack of attachment and rounded, refractile morphology. Scale bar, $50 \mu \mathrm{m}$. 


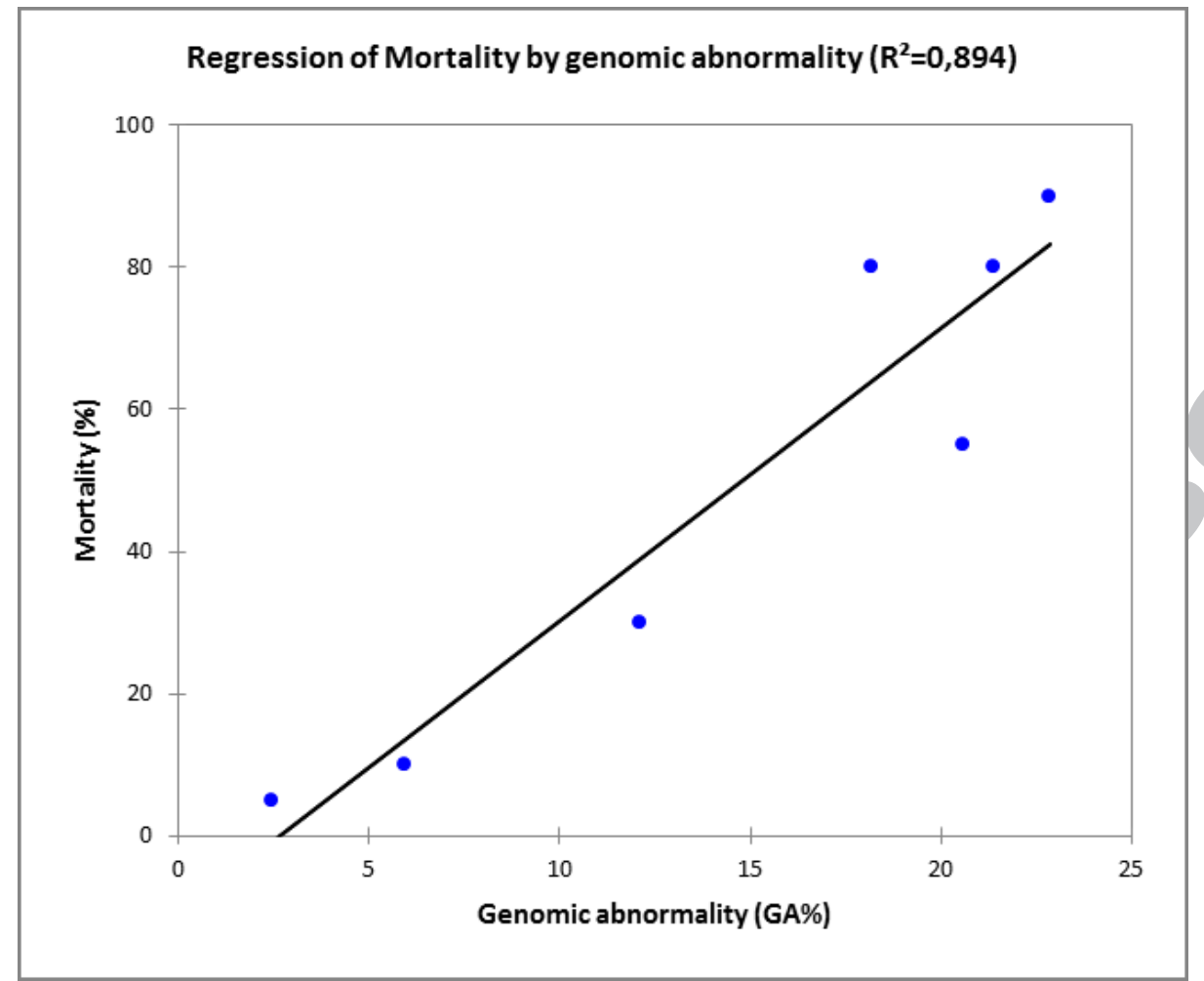

Figure 6. Simple regression between initial genomic abnormality level (GA\%) of blue mussel stocks from the field and final level of mortality (mortality \%) calculated in the hatchery condition. The equation of the regression is expressed as mortality $\%=(4.12 \times \mathrm{GA} \%)-$ 10.93 . 
Table 1. Result of the multiple pairwise comparisons using the Dunn's procedure on the distribution before the mortality of non-diploid nuclei percentages. $\mathrm{N}$ is the sample size. Samples with the same letter are not significantly different at $p=0.01$.

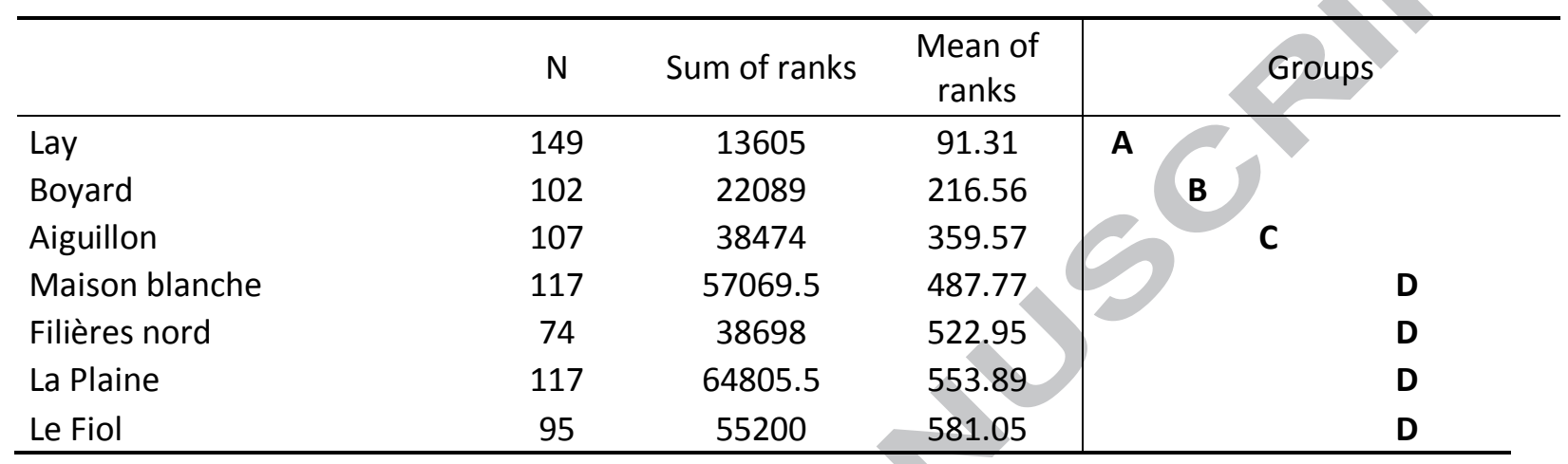


Graphical abstract
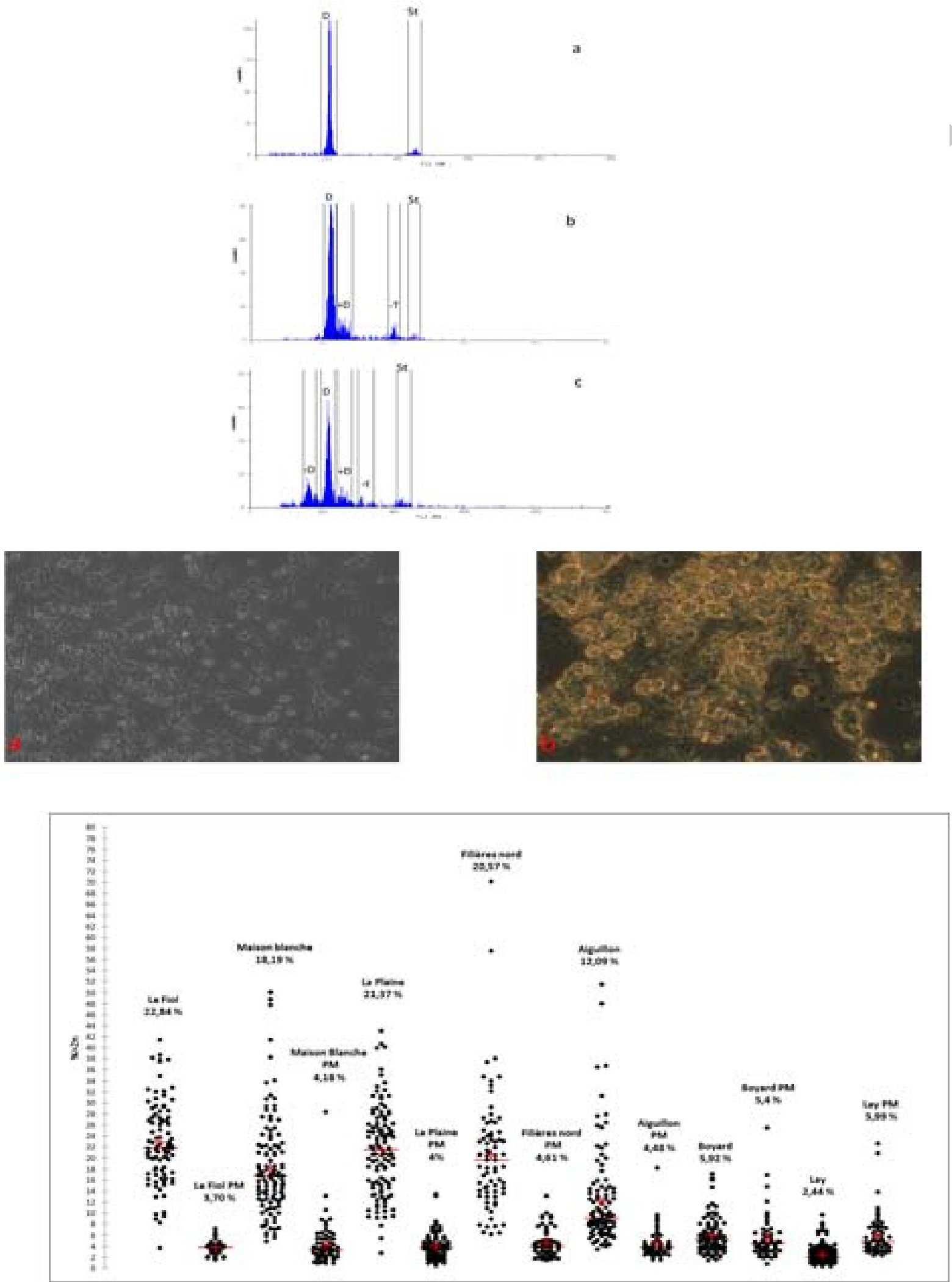